\title{
Chemsex. Un fenómeno emergente
}

\section{Chemsex. An emergent phenomenon}

\author{
Helen Dolengevich-Segal*, Beatriz Rodríguez-Salgado**, Jesús Ballesteros-López ***, Rocío \\ MOLINA-PRADO ****. \\ *Servicio de Psiquiatría. Hospital Universitario del Henares. Coslada (Madrid); **Hospital Ramón y Cajal. Centro de Salud \\ Mental de San Blas, Madrid; ***Hospital Universitario de Getafe. Madrid; **** Centro de Atención al Drogodependiente \\ Arganzuela. Madrid Salud.
}

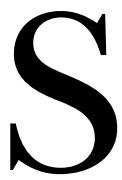
e conoce como chemsex al término proveniente del inglés (chemical sex), al uso intencionado de drogas psicoactivas para mantener relaciones sexuales, entre hombres que tienen sexo con hombres (HSH), habitualmente durante largos periodos de tiempo y con múltiples parejas. Este fenómeno también se ha denominado "Party and Play" ("PnP") en Norteamérica y en Australia "intensive sex partying" (Bourne et al., 2014). Se conoce como slamming o slamsex al uso de estas sustancias por vía intravenosa (IV). Las principales drogas utilizadas son mefedrona, $\gamma$-hidroxibutirato / $\gamma$-butirolactona (GHB/ GBL) y metanfetamina (McCall, Adams, Mason y Willis, 2015), aunque se han descrito otras (Véase tabla 1). Esta definición no llega a explicar aspectos fundamentales del fenómeno, como es el uso de aplicaciones sociales de geolocalización para encontrar o participar en "sesiones". De hecho, se ha descrito que los HSH que utilizan aplicaciones, en comparación con los que no lo hacen, tienden a ser más jóvenes, con mayor nivel educativo y mayor nivel adquisitivo, además de tener mayor probabilidad de involucrarse en conductas sexuales de riesgo y presentar más ETS (Zou y Fan, 2016).

Desde que McCall y sus colaboradores publicaron en 2015 en el BMJ la editorial What is chemsex and why does it matter, se han vertido diversas afirmaciones en medios de comunicación sobre el fenómeno, pero escasas publicaciones científicas en nuestro país, con lo que aún se desconoce la dimensión del mismo. Es desde el área de la infectología de donde han aparecido los artículos más significativos sobre el tema (Fernández-Dávila, 2016), señalando el in- cremento en las primoinfecciones de VIH en HSH y reinfecciones de hepatitis $\mathrm{C}$ en este colectivo, además de otras ETS. Es en HSH donde se ha dado la mayor proporción de nuevos diagnósticos de VIH en Europa en el año 2013, con un total de 42\% (Cornejo, Díaz, Díez y Valín, 2015). Asimismo, se ha descrito una elevada incidencia de reinfección por VHC en HSH de diferentes ciudades europeas, alcanzando tasas cercanas al 25\% (Ingiliz et al., 2016) con distintos factores de riesgo independientes: sexo anal sin protección, actividad sexual en el contexto de consumo de drogas estimulantes, prácticas sexuales de riesgo o sexo en grupo (Vanhommerig et al, 2015), características presentes en la práctica de chemsex.

Con respecto a las drogas utilizadas en chemsex, la mefedrona destaca con una prevalencia de consumo descrita de hasta un 90\% (Bourne et al., 2014). Esta sustancia, como otras catinonas sintéticas, cuenta con efectos psicoactivos y simpaticomiméticos similares a las anfetaminas, además de poseer propiedades entactógenas tales como intensificación sensorial, aumento de sociabilidad, desinhibición y excitación sexual. Su utilización tiene la finalidad de potenciar la estimulación sexual y la duración de sesiones (McCall, Adams, Mason y Willis, 2015). Su aparición en sesiones de slamsex se ha observado entre un 33 y un $38 \%$ en algunas series (Bourne et al., 2015). Esta sustancia cuenta con un gran potencial adictivo. En el consumo intravenoso, se ha descrito la necesidad de redosificar en periodos de tiempo cada vez más cortos, llegando hasta 15- 20 inyecciones al día. Además, esta vía favorece la presentación de sintomatología psicótica inducida. Por su parte, el GHB

Recibido: Octubre 2016; Aceptado: Febrero 2017.

Enviar correspondencia a:

Helen Dolengevich Segal. Servicio de Psiquiatría. Hospital Universitario del Henares. Avda. de Marie Curie s/n, 28822, Coslada (Madrid). Teléfono: 911912831. E-mail: e.dolengevich@gmail.com 
Tabla 1. Sustancias psicoactivas utilizadas en chemsex

\begin{tabular}{|c|c|c|c|c|c|c|c|}
\hline $\begin{array}{l}\text { Sustancia } \\
\text { psicoactiva }\end{array}$ & $\begin{array}{l}\text { Mefedrona y } \\
\text { otras catinonas } \\
\text { sintéticas: } \\
\text { pentedrona, } \\
\text { 4-MEC }\end{array}$ & Metanfetamina & GHB/GBL & $\begin{array}{l}\text { Nitritos } \\
\text { de alquilo/ } \\
\text { Butilo }\end{array}$ & MDMA & Cocaína & Ketamina \\
\hline $\begin{array}{l}\text { Nombres } \\
\text { populares }\end{array}$ & $\begin{array}{l}\text { Mefe, miau-miau, } \\
\text { met, sales de } \\
\text { baño. }\end{array}$ & $\begin{array}{l}\text { Tina, crystal } \\
\text { meth, vidrio, tiza, } \\
\text { cranck, speed. }\end{array}$ & Éxtasis líquido, G. & Poppers. & $\begin{array}{l}\text { Éxtasis, eme, } \\
\text { cristal, x. Sextasy } \\
\text { (con sildenafilo). }\end{array}$ & $\begin{array}{l}\text { Coca, blanca, } \\
\text { farlopa }\end{array}$ & $\begin{array}{l}\text { Keta, vitamina K, } \\
\text { Special } K \text {. }\end{array}$ \\
\hline $\begin{array}{l}\text { Efectos } \\
\text { buscados }\end{array}$ & $\begin{array}{l}\text { Estimulación, } \\
\text { excitación } \\
\text { sexual, euforia, } \\
\text { sentimientos de } \\
\text { empatía. }\end{array}$ & $\begin{array}{l}\text { Estimulación, } \\
\text { desinhibición, } \\
\text { excitación sexual, } \\
\text { incremento } \\
\text { de confianza y } \\
\text { autoestima. }\end{array}$ & $\begin{array}{l}\text { Sedación, } \\
\text { relajación } \\
\text { del esfínter } \\
\text { anal. Euforia, } \\
\text { desinhibición, } \\
\text { borrachera, } \\
\text { estimulación } \\
\text { sexual. }\end{array}$ & $\begin{array}{l}\text { Euforia, } \\
\text { socialización. } \\
\text { Excitación y } \\
\text { aumento de } \\
\text { potencia e } \\
\text { incremento de } \\
\text { placer sexual. }\end{array}$ & $\begin{array}{l}\text { Estimulación, } \\
\text { sentimientos } \\
\text { de empatía, } \\
\text { aceptación y } \\
\text { conexión. }\end{array}$ & $\begin{array}{l}\text { Activación, } \\
\text { excitación sexual, } \\
\text { hiperalerta. }\end{array}$ & $\begin{array}{l}\text { Estimulación } \\
\text { inicial, relajación, } \\
\text { empatía, mejora } \\
\text { de la percepción. } \\
\text { Disociación. }\end{array}$ \\
\hline
\end{tabular}

es un depresor del SNC que tiene un efecto desinhibidor percibido como afrodisiaco y una leve acción analgésica. Su efecto anestésico favorece la realización de prácticas sexuales agresivas como el fisting (sexo braqui-rectal) ya que relaja el músculo liso y disminuye el umbral doloroso. Las sobredosis con depresión respiratoria pueden ser frecuentes, dado que su efecto se potencia al combinarlo con otras sustancias y se acumula, lo que puede provocar pérdidas del estado de conciencia, lagunas de memoria y vulnerabilidad ante posibles abusos sexuales (Bourne et al., 2015). El uso de metanfetamina también es habitual, sobre todo vía IV. En este contexto, la metanfetamina incrementa la confianza sexual, duración e intimidad. También facilita la participación en conductas de alto riesgo, como sexo en grupo, con múltiples parejas, sexo en grupo o prácticas sexuales agresivas (Lea et al., 2016). El uso crónico de metanfetamina se asocia con un potencial elevado de dependencia, problemas de salud mental como depresión y/o psicosis, y contagio de virus sanguíneos, principalmente VIH (Darke, Kaye, McKetin y Duflou, 2008). El policonsumo de sustancias en habitual en la sesiones de chemsex, lo que incrementa los riesgos relacionados con el uso de estas drogas, además de las potenciales interacciones entre éstas y los tratamientos antirretrovirales utilizados por pacientes seropositivos.

Ante estos datos, pensamos que se hacen necesarios estudios epidemiológicos que evalúen el fenómeno en España, no sólo en el área de enfermedades infecciosas, sino también respecto al consumo de sustancias y sus repercusiones en salud mental. El abordaje multidisciplinar de estos usuarios, partiendo de enfoques dirigidos a la reducción de riesgos y de daños, hasta el tratamiento de las consecuencias del consumo de sustancias se hace ya necesario en nuestro país.

\section{Conflictos de intereses}

Los autores no presentan conflictos de intereses.

\section{Referencias}

Bourne, A., Reid, D., Hickson, F., Torres Rueda, S. y Weatherburn, P. (2014). The Chemsex study: drug use in sexual settings among gay \& bisexual men in Lambeth, Southwark \& Lewisham. London: Sigma Research, London School of Hygiene E Tropical Medicine. Recuperado de http://www.sigmaresearch.org.uk/chemsex.

Bourne, A., Reid, D., Hickson, F., Torres-Rueda, S., Steinberg, P. y Weatherburn, P. (2015). "Chemsex" and harm reduction need among gay men in South London. International Journal of Drug Policy, 26, 1171-1176. doi:10.1016/j.drugpo.2015.07.013.

Cornejo, A., Díaz, A., Díez, M. y Valín, E. R. (2015). Vigilancia epidemiológica del VIH/sida. Situación en Europa y en España, 2013. Boletín Epidemiológico Semanal, 22, 249-256.

Darke, S., Kaye, S., McKetin, R. y Duflou, J. (2008). Major physical and psychological harms of methamphetamine use. Drug and Alcohol Review, 27, 253-262. doi:10.1080/09595230801923702. 
Fernández-Dávila, P. (2016). "Sesión de sexo, morbo y vicio": una aproximación holística para entender la aparición del fenómeno ChemSex entre hombres gais, bisexuales y otros hombres que tienen sexo con hombres en España. Revista Multidisciplinar del Sida, 4, 41-65.

Ingiliz, P., Martin, T., Rodger, A., Stellbrink, H.J., Mauss, S., Boesecke, C. ... the NEAT Study Group. (2016). Hepatitis $\mathrm{C}$ virus reinfection incidence and outcomes among HIV-positive MSM in Western Europe. International Liver Congress, Abstract PS006. Barcelona.

Lea, T., Mao, L., Hopwood, M., Prestage, G., Zablotska, I., de Wit, J. y Holt, M. (2016). Methamphetamine use among gay and bisexual men in Australia: Trends in recent and regular use from the Gay Community Periodic Surveys. International Journal of Drug Policy, 29, 66-72. doi:10.1016/j.drugpo.2016.01.003.

McCall, H., Adams, N., Mason, D. y Willis, J. (2015). What is chemsex and why does it matter? British Medical Journal, 351, h5790. doi:10.1136/bmj.h5790.

Vanhommerig, J.W., Lambers, F.A., Schinkel, J., Geskus, R.B., Arends, J.E., van de Laar, T.J., ... Prins, M. (2015). Risk Factors for Sexual Transmission of Hepatitis C Virus Among Human Immunodeficiency Virus-Infected Men Who Have Sex With Men: A Case-Control Study. Open Forum Infectious Diseases, 2. doi:10.1093/ofid/ofv115.

Zou, H., y Fan, S. (2016). Characteristics of Men Who Have Sex With Men Who Use Smartphone Geosocial Networking Applications and Implications for HIV Interventions: A Systematic Review and Meta-Analysis. Archives of Sexual Behavior. Avance de publicación on-line. doi:10.1007/s10508-016-0709-3. 